\title{
Cardápio educativo no Instituto Federal de Rondônia: prática do ensino da Língua Espanhola no Campus Jaru
}

\section{Educational menu at the Federal Institute of Rondônia: practice of teaching the Spanish language on the Jaru Campus}

\author{
Robson Fonseca Simões 1 \\ Osvaldo Homero Garcia Cordero 2
}

\begin{abstract}
Resumo
$\mathrm{Na}$ tentativa de contribuir para o debate pedagógico que traga à tona práticas educativas de um professor do Ensino Técnico-Médio de Alimentos do Instituto Federal de Rondônia, Campus Jaru, este estudo procura apresentar ações pedagógicas propositivas de espanhol, inspirado em estudos dos pesquisadores, tais como Fiorin (2008) e Bakhtin (1999) sobre a linguagem, o ensino de língua estrangeira moderna e os documentos oficiais da educação. 0 Cardápio Educativo entende que a língua se movimenta na vida dos sujeitos através dos enunciados concretos que a realizam, abrindo portas para as reflexões iniciais de uma pesquisa de mestrado, em uma universidade rondoniense. Mas quais são os desafios a serem enfrentados pelos educadores para refletir sobre o ensino da língua espanhola e a formação dos discentes? As práticas pedagógicas com a língua estrangeira moderna pedem passagem para a formação humana no Ensino Profissional. $\mathrm{Na}$ interação em diferentes instituições sociais, o educando aprende as formas de funcionamento das línguas no ambiente plurilinguístico da Região Amazônica. Marcuschi (2006), Bakhtin (2012), Candau (2012) e Hall (2013) ajudam-nos a refletir que os diálogos entre a linguagem e a vida nascem nas práticas sociais, o que nos permite abordar a discussão sobre 0 ensino do espanhol na última etapa da Educação Básica da Amazônia Ocidental.
\end{abstract}

Palavras-chave: Língua espanhola. Linguagem. Educação.

\section{Resumen}

En un intento de contribuir al debate pedagógico que plantea las prácticas educativas de un profesor de la Escuela Técnica Superior de Alimentación del Instituto Federal de Rondônia, campus Jaru, este estudio busca presentar acciones pedagógicas proposicionales en español inspiradas en los estudios de investigadores, como Fiorin (2008) y Bakhtin (1999) sobre el lenguaje, sobre la lengua, la enseñanza de lenguas extranjeras modernas y los documentos oficiales de educación. El menú educativo entiende que el lenguaje se mueve en la vida de los sujetos a través de los enunciados concretos que lo hacen, abriendo puertas a las reflexiones iniciales de una investigación de Máster, en una universidad de Rondônia. Pero, ¿cuáles son los retos a los que se enfrentan los educadores para reflejar la enseñanza de la lengua española y la formación de los estudiantes? Prácticas pedagógicas con la lengua extranjera moderna reclaman el paso a la formación humana en la Educación Profesional. Al interactuar en diferentes instituciones sociales, el alumno aprende las formas en que funcionan los idiomas en un entorno multilingüe en la región amazónica. Marcuschi (2006), Bakhtin (2012), Candau (2012) y Hall (2013) ayudan a reflexionar que los diálogos entre lengua y vida nacen en las prácticas sociales, lo que permite abordar la discusión sobre la enseñanza del español en los últimos tiempos. etapa de Educación Básica de la Amazonía Occidental.

Palabras claves: Lengua española. Lenguaje. Educación.

1Pós-Doutorado em Educação. Universidade Federal de Rondônia, Porto Velho, Rondônia, Brasil. Orcid: https://orcid.org/0000-0003-0046-9549. E-mail: robson.simoes@unir.br.

2Mestrando do Programa de Pós-Graduação em Educação Escolar, Mestrado Profissional da Universidade Federal de Rondônia. Instituto Federal de Educação, Ciência e Tecnologia de Rondônia, campus Jaru, Rondônia, Brasil. Orcid: https://orcid.org/0000-0001-7411-3719. E-mail: osvaldo.homero@ifro.edu.br.

LínguaTec, Instituto Federal de Educação, Ciência e Tecnologia do Rio Grande do Sul, Bento Gonçalves v. 6 , n. 1, p. 109-123, jun. 2021. 


\section{Pensar a língua espanhola, pensar a educação: considerações iniciais}

"As coisas findas muito mais que lindas, essas ficarão." (Carlos Drummond de Andrade, 2012, p. 21)

A epígrafe deste estudo pode ser um ponto de partida para entabularmos um debate pedagógico que aborde as ações educativas no âmbito do ensino de Língua Espanhola na última etapa da Educação Básica, mais especificamente no Ensino Técnico-Médio de Alimentos, do Instituto Federal de Rondônia (IFRO), Campus Jaru. Como um aceno para os professores, que trabalham a Língua Estrangeira Moderna no Ensino Técnico, a voz poética pode inspirá-los a ver com outros olhos, ações propositivas que auxiliem os sujeitos, tanto no universo escolar quanto em seu cotidiano vivido, diante das discussões sobre as formas de estar no mundo compatíveis com o meio sociocultural em que estão inseridos (OLIVEIRA; SGARB, 2002).

A educação entra em cena no debate acadêmico a partir de ações pedagógicas propositivas com a Língua Espanhola, do suporte teórico de diversos estudiosos, pertencentes às mais diferentes áreas do conhecimento, e de suas contribuições para o discurso e as práticas educativas com este idioma; em outras palavras: a partir da pluralidade intercultural (CANDAU, 2012), das mediações culturais (HALL, 2013) nas terras da Amazônia Ocidental, das linguagens (MARCUSCHI, 2006) e do entrelaçamento dialógico (BAKHTIN, 2012) com outros saberes e culturas sociais.

Nesse viés, o presente trabalho procura relatar as ações pedagógicas de um professor iniciante no âmbito do Ensino Profissional, mais especificamente no Curso Técnico-Médio de Alimentos do IFRO, Campus Jaru, em projeto intitulado Cardápio Educativo, cujo objetivo foi fortalecer o domínio das habilidades linguísticas nesse idioma estrangeiro. Entende-se que a língua se movimenta na vida dos sujeitos através dos enunciados concretos que a realizam; assim sendo, faz-se presente em aspectos culturais, artísticos, linguísticos, esportivos, econômicos, entre outros. Essa relação dialógica possibilita ao professor despertar o interesse dos alunos pela língua estrangeira, tomada como alternativa, no esforço de fazer com que desenvolvam habilidades e formas expressivas inscritas no mundo cultural que os cerca. É possível se debruçar sobre a teoria dialógica em uma região de grande diversidade linguística-cultural, que traz à tona a ideia de que a língua se produz em meio às práticas e relações sociais, sublinhando que o fundamento de toda linguagem é o dialogismo, essa relação com o outro.

A escola e o professor questionam-se e são questionados sobre o papel que lhes cabe diante dos desafios do ensino de Língua Estrangeira Moderna na Educação Básica. Se a voz de Rosa (1985, 
p. 74) também for invocada para este debate - "para estas duas vidas, um léxico só não é suficiente" -, quem sabe, seja para oferecer ângulos de visibilidade educativa diferenciados, considerando a linguagem como instrumento que permeia as práticas sociais (BAKHTIN, 1999) e concebendo a instituição escolar como espaço para o acesso à cultura e à ciência. Nessa acepção, fazem-se necessárias ações educativas diferenciadas, sobretudo no contexto intercultural amazônico, num esforço para desatar os possíveis nós pedagógicos do ensino de Língua Espanhola na última etapa da Educação Básica amazonense.

Diante dessa perspectiva, Fiorin (2008) afirma que o modo de uso da língua está ligado a processos sociais e culturais mais amplos; é possível observar que as práticas de linguagem articulam palavras e sentidos, criam valores, costumes e culturas. Por sua vez, os estudos de Sandmann (1990) anunciam que as práticas de linguagem são habilidades sociais que, fazendo uso de diferentes discursos, além de significarem e comunicarem, abrem espaços para o protagonismo dos sujeitos.

Não é difícil entender que a linguagem está inserida em todas as áreas do conhecimento humano; mas quais são os desafios a serem enfrentados pelos educadores para que possam refletir sobre 0 ensino e a aprendizagem da língua espanhola na formação dos sujeitos? Nessa relação viva com os seres humanos, é possível refletir que os diálogos entre a linguagem e a vida nascem nas práticas sociais, abrindo portas para novas ações educativas na última etapa da Educação Básica da Amazônia Ocidental, numa fronteira geográfica com vários países que apresentam a língua espanhola como idioma oficial.

Se, por um lado, a Base Nacional Comum Curricular (BNCC) (BRASIL, 2018a), um dos documentos oficiais da educação brasileira, acena com possibilidades e estratégias diferenciadas no esforço de trabalhar os conteúdos nos contextos em que pareçam necessários e ainda considera os sujeitos falantes e suas circunstâncias, como a região em que estão inseridos, por outro lado, percebese um número reduzido de docentes de Língua Espanhola nas instituições, bem como de aulas na carga horária dos cursos.

Adiantando esta realidade, os Parâmetros Curriculares Nacionais de Língua Estrangeira (BRASIL, 1998) já anunciavam a difícil situação em que o ensino se encontrava, em vista de problemáticas como a falta de materiais adequados, as classes lotadas, o número reduzido de aulas por semana, assim como a ausência de ações formativas contínuas para o corpo docente, deslindando um cenário repleto de desafios a serem superados pelos educadores.

Tendo em vista que "[...] a sala de aula não é uma redoma de vidro, isolada do mundo, e o que acontece dentro da sala de aula está condicionado pelo que acontece lá fora" (LEFFA, 2001, p. 336), 0 Projeto envolveu uma turma do segundo ano do Curso de Alimentos, no ano de 2019. Com o objetivo 
de dialogar com as diversidades linguísticas, culturais e alimentícias, o Cardápio Educativo procurou instigar nos estudantes o diálogo com a vida, priorizando processos educativos capazes de gerar sujeitos inventivos, participativos, cooperativos epreparados para inserções sociais, políticas, culturais e laborais.

\section{Desafios educativos: Língua Espanhola para a formação humana}

O IFRO é uma autarquia federal vinculada ao Ministério da Educação (MEC); foi criado pela Lei $n^{0}$ 11.892, de 29 de dezembro de 2008, que reorganizou a Rede Federal de Educação Profissional, Científica e Tecnológica. Permanecem como centros Federais de Educação Tecnológica, o CEFET- RJ e o CEFET-MG; o CEFET Paraná-PR passou a ser a Universidade Tecnológica do Paraná. Trata-se de uma instituição especializada na oferta de Educação Profissional e Tecnológica que também atua na Educação Básica e no Ensino Superior, na pesquisa e no desenvolvimento de produtos e serviços, em estreita articulação com a sociedade.

Geograficamente, o IFRO está presente em vários municípios do estado de Rondônia, a saber: Ariquemes, Cacoal, Colorado do Oeste, Guajará-Mirim, Jaru, Ji-Paraná, São Miguel do Guaporé, Porto Velho, Zona Norte, Calama e Vilhena. Na Figura 1, a seguir, tem-se um panorama geográfico da cidade de Jaru, um dos municípios do estado de Rondônia em que o IFRO está localizado, numa tentativa apresentar um pouco mais o seu território:

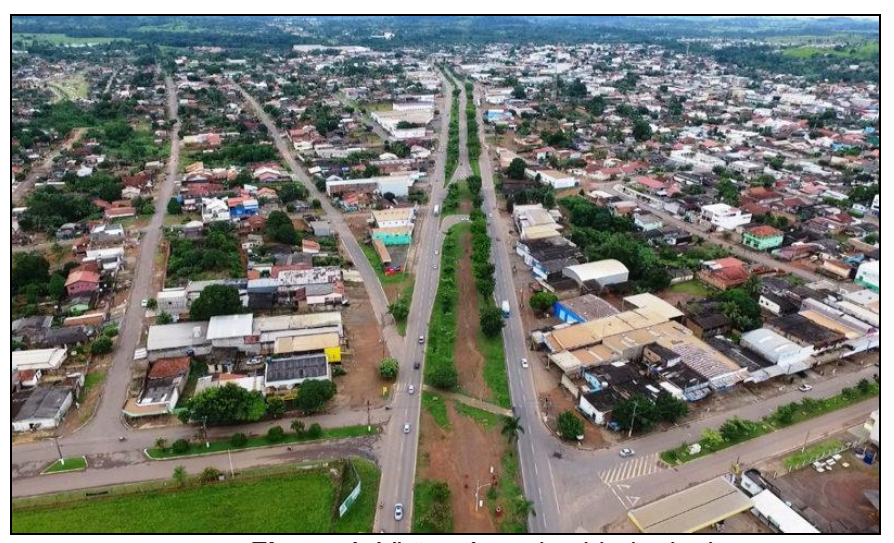

Figura 1. Vista aérea da cidade de Jaru.

Fonte: https://google.com/cardapiodigitalemjaru,ro. Acesso em: 02 mar 2021.

O município de Jaru foi criado pela Lei n 6.921, de 16 de junho de 1981 (BRASIL, 1981), e seu nome é uma homenagem ao rio homônimo e à nação indígena dos Jarus. Está situado às margens da BR-364, que corta o estado de Rondônia de Norte a Sul. Geograficamente, Jaru está localizado 
próximo às cidades de Ji-Paraná e de Ariquemes, importantes centros regionais do estado de Rondônia; a população do município, de acordo com estimativas do Instituto Brasileiro de Geografia e Estatística (IBGE), chegou a 51. 933 habitantes em 2018.

O Campus Jaru do IFRO, em franco processo de expansão do seu atendimento à população do município, oferece os seguintes Cursos Técnicos Integrados ao Ensino Médio: Alimentos, Comércio e Segurança do Trabalho. Além de Cursos Técnicos Subsequentes de Agronegócio, Comércio e Segurança do trabalho e de um Bacharelado em Medicina Veterinária. Na Figura 2, a seguir, apresenta-se a fachada do IFRO, Campus Jaru, RO:

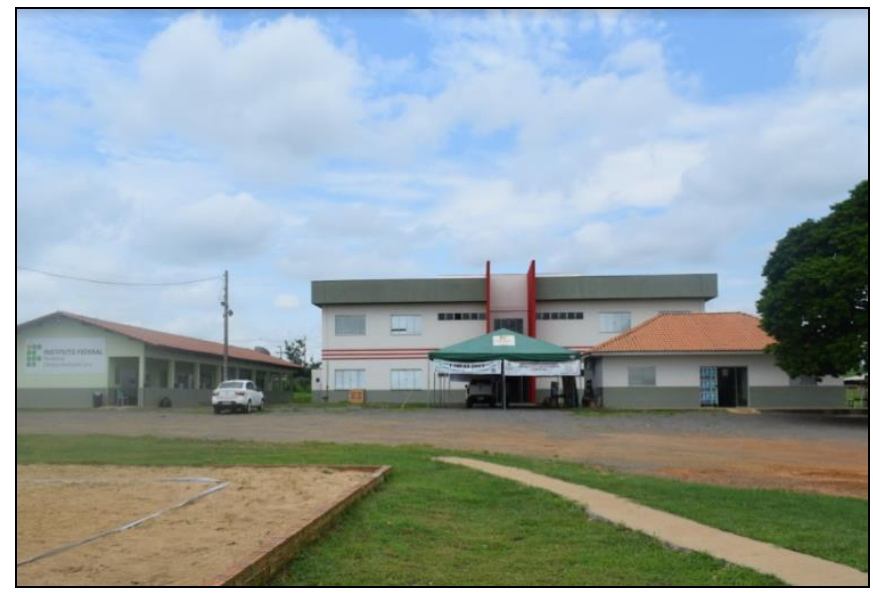

Figura 2. IFRO, Campus Jaru, RO.

Fonte: arquivo cedido aos autores pela Secretaria de Comunicação do IFRO, Campus Jaru, RO (2019).

A imagem acima deixa entrever que os espaços e as instalações do IFRO, Campus Jaru, podem produzir um diálogo com a natureza, proporcionando aos servidores, pesquisadores, educadores e estudantes a inspiração para a busca da qualidade do ensino, da pesquisa e da extensão nas terras rondonienses.

Quando o assunto é o Plano de Desenvolvimento Institucional (PDI), a proposta pedagógica do IFRO (2018) leva em consideração as demandas sociais, econômicas e culturais, englobando questões sobre diversidade cultural, preservação ambiental e os novos modelos de desenvolvimento sustentável para o planeta, em particular para a Região Amazônica. A instituição prima pela formação de cidadãos capazes de construir suas histórias de vida, preparados para o pleno exercício da cidadania e para 0 trabalho, tendo em vista os seguintes valores: sensibilidade, autenticidade, autonomia, criatividade, solidariedade e respeito, o que remete à BNCC (BRASIL, 2018a).

De acordo com Ramos (2014), historicamente, a organização da Rede de Ensino TécnicoProfissional se originou na última década da Primeira República, quando começou a despontar a 
preocupação com os padrões de ensino e cultura nas diferentes modalidades e nos diferentes níveis das instituições escolares, período visto por alguns autores como de entusiasmo e otimismo pedagógicos, abrindo portas para a temática da instrução nos seus diversos níveis (NAGLE, 1976).

Se olharmos para a historiografia da educação, perceberemos que o século XX foi o porta-voz do trabalho, do saber-fazer. A Lei de Diretrizes e Bases da Educação Nacional (LDB) (BRASIL, 1996) sublinhou o âmbito da educação como um espaço para o desenvolvimento da economia de mercado, e o Decreto n².208, de 17 de abril de 1997 (BRASIL, 1997) regulou a Educação Profissional. Nesse sentido, trata-se do valor aspirado pelos sujeitos que desejam obter um saber que lhes garantirá sucesso imediato em suas vidas profissionais.

O século XXI trouxe novas questões no que diz respeito à Educação Profissional de Nível Médio; vale destacar que muitos autores têm se debruçado e discutido sobre o Decreto $n^{0} 5.154$, de 23 de julho de 2004 (BRASIL, 2004), que trouxe à tona esta temática. Nele estão impressos os possíveis sentidos de um projeto cujo intento é integrar a Educação Profissional Técnica de Nível Médio ao Ensino Médio.

O Decreto $n^{0}$ 6.302, de 12 dezembro de 2007, instituiu o Programa Brasil Profissionalizado (BRASIL, 2007b), visando estimular o Ensino Médio Integrado à Educação Profissional, com ênfase na educação científica e humanística, por meio da articulação entre formação geral e educação profissional, considerando a realidade concreta no contexto dos arranjos produtivos e as vocações sociais, culturais e econômicas locais e regionais. Vale destacar que:

Assim, a história da humanidade é a história da produção da existência humana e a história do conhecimento é a história do processo de apropriação social dos potenciais da natureza para o próprio homem, mediada pelo trabalho. Por isso, o trabalho é mediação ontológica e histórica na produção de conhecimento (BRASIL, 2007a, p. 42).

Educação Profissional, portanto, é um termo usado para qualificar esta modalidade de ensino, atribuindo-lhe o sentido de princípio educativo, e não pura e simplesmente um meio de formar mão de obra qualificada. Ela confere ao ser humano a propriedade de transformar a sua própria realidade, e não apenas perpetuar a estrutura social vigente. Permite que o aprendiz se aproprie do saber-fazer, a fim de consolidar sua própria identidade, levando em conta sua história e seus valores culturais. Nesse viés, as reflexões de Saviani (2011, p. 9) sublinham que:

Portanto, quando o trabalho é considerado como princípio educativo, estamos querendo dizer que o trabalho, enquanto elemento fundante e determinante da vida humana em seu conjunto é, por consequência, fundante e determinante da educação. Ou seja: uma vez que o trabalho é "condição natural eterna da vida humana", em qualquer sociedade o trabalho se comporta como princípio educativo, isto é, determina a forma como é constituída e organizada a educação. 
Segundo Carlou (2014), em 1942, Gustavo Capanema promoveu uma reforma no sistema educacional brasileiro, equiparando o Ensino Profissional e Técnico ao Ensino Médio. Na mesma ocasião, os Liceus Industriais passaram a se chamar Escolas Industriais e Técnicas (EIT), modelo que prevaleceu até 1959, ocasião em que as ElTs foram transformadas em Escolas Técnicas Federais $(E T F)$, ganhando autonomia pedagógica e administrativa. Pouco depois, o Ensino Técnico ganharia um novo status: o Ensino Profissional alcançaria o Ensino Superior, por força da LDB/1996.

Em 1978, surgiram os três primeiros Cefets, que tinham como objetivo formar engenheiros de operação e tecnólogos, que logo se tornariam a unidade padrão da Rede Federal de Ensino Profissional, Científico e Tecnológico (IF). Após trinta anos, em 2008, os IFs foram criados para absorver os Cefets e as Escolas Técnicas remanescentes. Em vista disso, o Decreto-Lei $n^{0} 11.892$, de 29 de dezembro de 2008 (BRASIL, 2008), criou 38 IFs, entre os quais o Instituto Federal de Educação, Ciência e Tecnologia do Amazonas (IFAM). E sobre o ensino de Língua Espanhola?

Entre 1942 e 2005, ano em que foi promulgada a Lei $n^{0} 11.161$, de 5 de agosto (BRASIL, 2005), que dispunha sobre o ensino deLíngua Espanhola, a implantação do ensino deste idioma foi marcada por certa irregularidade, alternado instantes de ausência e presença dentro dos currículos nacionais da educação brasileira. Entretanto, doze anos depois, no governo de Michel Temer, a Lei $n^{0}$ 11.161/2005 foi revogada pela Lei $n^{0} 13.415$, de 16 de fevereiro de 2017, que, entre diversos propósitos, alterou a LDB/1996. Esta nova lei, em seu artigo 35-A, redefiniu os direitos e objetivos de aprendizagem do Ensino Médio, de acordo com diretrizes do Conselho Nacional de Educação (CNE). Em seu parágrafo $4^{\circ}$, o referido artigo estabeleceu que os currículos do Ensino Médio incluirão, obrigatoriamente, o estudo da língua inglesa e poderão ofertar outras línguas estrangeiras, em caráter optativo, preferencialmente o espanhol, de acordo com a disponibilidade de oferta, locais e horários definidos pelos sistemas de ensino (BRASIL, 2017).

Na BNCC (BRASIL, 2018a), estão as aprendizagens essenciais, organizadas por áreas do conhecimento. No caso da língua espanhola, ela está inserida na área de 'linguagens e suas tecnologias' e acompanha a reforma das Diretrizes Curriculares Nacionais para o Ensino Médio (DCNEM) (BRASIL, 2018b), que contemplam o itinerário de formação técnica e profissional, com a recomendação de estudos e práticas a serem desenvolvidos através de projetos contextualizados e interdisciplinares".

As DCNEM estabelecem que, na formação geral básica, devem ser contemplados estudos e práticas de língua inglesa, sem prejuízo da integração e articulação entre as diferentes áreas do conhecimento, podendo ser oferecidas outras línguas estrangeiras, em caráter optativo, 
preferencialmente o espanhol, de acordo com a disponibilidade da instituição ou rede de ensino

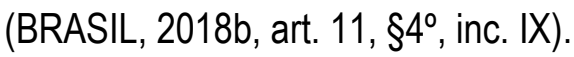

Consideramos necessário apresentar estratégias para a retomada e a valorização da disciplina dentro da sala de aula, mesmo sabendo dos entraves curriculares para o ensino de Língua Espanhola. Nesse sentido, é possível apostar em novas experiências, nos diálogos com os aprendizes e na reflexão com as práticas pedagógicas.

O Curso Técnico de Alimentos Integrado ao Ensino Médio do IFRO, Campus Jaru, tem em sua grade curricular disciplinas das áreas técnicas, das áreas específicas, do estágio obrigatório e das áreas das ciências humanas e sociais. 0 espanhol, como se pode examinar a seguir, é oferecido no segundo ano letivo:

\begin{tabular}{|c|c|}
\hline PLANO DE DISCIPLINA & \\
\hline CURSO: TÉCNICO EM ALIMENTOS INTEGRA & INO MÉDIO \\
\hline DISCIPLINA: ESPANHOL & \\
\hline NÚCLEO DE FORMAÇÃO: DIVERSIFICADA & ANO: $2^{\circ}$ \\
\hline CARGA HORÁRIA TOTAL: 80h & Carga Horária Teórica: 80h \\
\hline Carga Horária Semanal: $2 \mathrm{~h}$ & Carga Horária Prática: - \\
\hline Objetivo geral & \\
\hline $\begin{array}{l}\text { Desenvolver a leitura, a compreensão auditiva, } \\
\text { cultural aprendido na prática (das relações socic }\end{array}$ & $\begin{array}{l}\text { dução escrita aplicandoo conteúdo gramatical, léxico e } \\
\text { nais), em língua espanhola. }\end{array}$ \\
\hline Objetivos específicos & \\
\hline Ler textos em espanhol e extrair deles a ideia pr & um olhar crítico; \\
\hline Reconhecer a estrutura gramatical em uso na lí & \\
\hline $\begin{array}{l}\text { Compreender vocabulários vários que sejam rel } \\
\text { profissões, esportes, etc.; }\end{array}$ & s diversas atividadescotidianas, objetos, alimentos, \\
\hline Reconhecer e aprender noções de gramática da & anhola; \\
\hline Reconhecer e aplicar regras relativas a verbos, & sses correlatas. \\
\hline EMENTA & \\
\hline $\begin{array}{l}\text { Castellano o español. Alfabeto: letras y sonidos } \\
\text { Las preposiciones. Pronombres personales y } \\
\text { Pronombres relativos. Pronombres posesivos. F } \\
\text { Lugares y medios de transporte. Numerales ca } \\
\text { del año. Las estaciones del año. Los días de } \\
\text { expresiones adverbiales. Vocabulario de la cas } \\
\text { Heterosemánticos. Heterogenéricos. Heterotóni } \\
\text { bebidas. Adjetivo: género y número. Los si } \\
\text { Vocabulario del cuerpo humano. Pronombres } \\
\text { deportes. Componentes culturales de España } \\
\text { formas (la comida, las danzas, las fiestas po } \\
\text { costumbres, la música, la literatura, las actividac }\end{array}$ & $\begin{array}{l}\text { acionalidades. Los artículos determinados e indeterminados. } \\
\text { to. Pronombres interrogativos. Pronombres demostrativos. } \\
\text { formal/informal. La familia. Contracciones y combinaciones. } \\
\text { merales ordinales. Artí́culo neutro -lo. Colores. Los meses } \\
\text { Las horas. El sustantivo: género y número. Adverbios y } \\
\text { clase y la calle. Verbos regulares e irregulares en presente. } \\
\text { s y profesiones. Verbo gustar. Vocabulario de las comidas y } \\
\text { ntuación. Reglas de eufonía. Vocabulario del vestuario. } \\
\text { Apócopes. El uso de muy y mucho. Vocabulario de los } \\
\text { ses hispánicos: las manifestaciones culturales en todas sus } \\
\text { puntos turísticos, las luchas de clases, la agricultura, las } \\
\text { etc.). }\end{array}$ \\
\hline & \\
\hline
\end{tabular}


BOM, Francisco Matte. Gramática comunicativa delespañol. Madri:Edelsa, 1995.v. 1 e 2.

COIMBRA, Ludmila. Cercaníajoven: espanhol, $1^{\circ}$ ano: ensino médio. São Paulo: SM, 2013.

MILANI, Esther Maria. Gramática de espanhol para brasileiros. São Paulo: Saraiva, 2003.

MILANI, Esther Maria. Listo: español a través de textos. São Paulo: Moderna, 2005.

\section{Referências complementares}

DICCIONARIOde la Lengua Española. São Paulo: Larousse, 1997.

COIMBRA, Ludmila. Cercaníajoven: espanhol, $1^{\circ}$ ano: ensino médio. São Paulo: SM, 2013.

GRAMÁTICA da Língua Espanhola. São Paulo: Escala Educacional, 2004. (Col. Manuais Práticos).

LLORACH, Emílio Alorcos. Gramática de La LenguaEspañola. Madrid: Espasa Calpe, 1995.

LLUCH ANDRÉS, Antoniet al. Materialesdidácticos para laenseñanzade Español. Brasília, DF: Educación, 2008.

REVISTA IALIMENTOS. Bogotá: Axioma Comunicaciones, 2012-. Disponivel em:

http://revistaialimentos.com.co/digitales.

REVISTA INDUSTRIA ALIMENTARIA. Lima: Food\& Health Consulting, 2017-. Disponivel em:

http://www.industriaalimentaria.org/http://www.revistaalimentaria.es/.

\section{Quadro 1. Plano da disciplina Língua Espanhola no IFRO, Campus Jaru.}

Fonte: IFRO, Campus Jaru (2020).

Analisando-se o plano da disciplina de Língua Espanhola para os estudantes do Curso Técnico-Médio de Alimentos do IFRO, Campus Jaru, conclui-se que as 80 horas oferecidas durante 0 segundo ano conformam uma carga horária bastante reduzida, com apenas duas horas semanais, em que pese 0 esforço de trabalhar a escrita, a leitura e as práticas com o espanhol.

O (re)desenho do ensino da língua espanhola, com projetos educativos que objetivam contemplar a cultura, as tecnologias, as especificidades das áreas técnicas, as linguagens e os saberes amazônicos, pode ser um ponto de partida no esforço de fazer com que, na disciplina, não se esgoteem ações educativas prescritivas, ou seja, aquelas que se estabelecem em um único aspecto linguístico tido como aceitável, a fim de que, sobretudo, dialogue com os diversos saberes envolvidos no desenvolvimento humano, valorizando a criatividade e o protagonismo dos sujeitos no âmbito do ensino e do aprendizado do espanhol.

\section{Invitación del chef para degustar: práticas de espanhol na sala de aula}

Os sujeitos são atravessados pelos mais variados sistemas de textos, em suas diferentes materialidades e suportes (CHARTIER, 2003), obrigando-os a produzirem saídas e táticas (CERTEAU, 1994) capazes de fazer com que se movam em todos os espaços sociais. Além de criarem sistemas próprios de significação, passam a apreender e a (res)significar outros códigos presentes na vida.

Celada (2002) alerta que a língua não pode se restringir a um número de dificuldades gramaticais a serem superadas; a autora sugere que, quando surgem dificuldades no ensino, estas 
podem ser superadas por estratégias pedagógicas que compõem a estrutura técnico-metodológica a qual é submetida a língua de estudo.

Por sua vez, Zeichner (1993) sugere que a compreensão e a melhoria do ensino começam pela reflexão sobre a própria experiência, e que este procedimento de aprender a ensinar acompanha 0 educador. Nessa acepção, foi-nos possível, a partir das experiências educativas com a língua espanhola em outras instituições de ensino, (re)pensar as práticas pedagógicas deste idioma no âmbito do IFRO, Campus Jaru, com projetos voltados para a vida profissional dos sujeitos.

Os estudos de Arroyo (2013) ajudam-nos a refletir sobre a importância de práticas que possibilitem o diálogo com projetos educativos. Mesmo sabendo da resistência que existe nas instituições de ensino quando o debate é a (des)construção e o (re)ordenamento da transmissão dos conteúdos, é possível (re)avaliar a tendência de realizar aulas mecânicas, acompanhadas por apostilas ou aulas expositivas tradicionais, bem como dar-se à ousadia de promover ações educativas significativas para os educandos do IFRO. Em vista disso, optamos por um projeto que valorizasse 0 protagonismo dos discentes e a criatividade dos sujeitos.

A legislação educacional brasileira, sobretudo a LDB/1996, insere a educação profissional e tecnológica no quando mais amplo dos direitos do cidadão à educação e ao exercício da cidadania, instigando-nos a refletir sobre a formação humana no Ensino Técnico-Médio.

Essa primeira experiência educativa no IFRO, Campus Jaru, foi realizada no ano letivo de 2019, com 40 estudantes regularmente matriculados no segundo ano do Curso Técnico-Médio de Alimentos. O Cardápio Educativo contou com as seguintes etapas: 'preparando os ingredientes', 'de olho na cultura culinária', 'pensar uma proposta gourmel' e o 'momento da degustação'.

O Projeto buscou construir diálogos que reforçassem o processo de ensino-aprendizagem de Língua Espanhola a partir da interação com outros conhecimentos, a fim de romper, dessa forma, o isolamento dos conteúdos disciplinares.

O conteúdo discutido com a turma durante os encontros teve por objetivo trabalhar o léxico pertinente aos alimentos e às bebidas da Região Hispano-Americana ao longo do preparo de uma receita culinária. Os sujeitos optaram por gravar as atividades com o auxílio de seus celulares, visando a apresentar o preparo das comidas em sala de aula ao estilo do programa Master Chef, transmitido por uma grande emissora de televisão. A orientação metodológica definiu que a gravação deveria ser realizada em espanhol e dentro de um tempo estipulado. Nessa acepção, as reflexões de Certeau (1994) ajudam-nos a pensar sobre a arte de dizer, fazer e pensar do sujeito.

Durante o segundo semestre de 2019, os conteúdos de classe e extraclasse da disciplina de Língua Espanhola foram contextualizados em atividades de ensino e pesquisa que envolveram as 
culturas culinárias e os seus diálogos com a Região Amazônica. Vale destacar que, durante 0 desenvolvimento do projeto, os discentes tiveram a liberdade de explorar os conteúdos e as divisões das tarefas, assim como as apresentações finais.

A fase da proposta gourmet, realizada em grupos, procurou fortalecer didaticamente a pronúncia da língua espanhola; dessa vez, a aproximação foi com as habilidades linguísticas. Bakthin (2012) sinaliza que vivenciar as múltiplas situações comunicativas favorece 0 contato com diversos gêneros, e que isso faz parte de um exercício para solidificar acompetência linguística. Por sua vez, Marcuschi (2006) reflete que a oralidade sempre será, ao lado da escrita, o grande meio de expressão discursiva e da atividade comunicativa dos sujeitos.

O processo de elaborar um cardápio de forma prática convida-nos a apresentar alguns elementos necessários para sua efetivação. Assim, as apresentações dos trabalhos valeram-se de recursos tecnológicos tais como: aparelho celular, data show, notebook e caixa acústica.

Durante a apresentação dos trabalhos, pairava o silêncio; um indicativo da cumplicidade de todos para com a proposta. Foi possível observar a dedicação dos alunos durante a apresentação dos trabalhos, no esforço de trabalhar os diálogos e vocábulos da língua espanhola, assim como as expressões idiomáticas. 0 papel do professor oscilava entre a observação e a intervenção, no sentido de pontuar alguns elementos que pudessem complementar o trabalho realizado pelos discentes (PERRENOUD, 2000).

Surgiram os mais diversos pratos, de diferentes países hispano-americanos, com dicas para a preparação, variedades de alimentos alternativos para pessoas com diabetes, hipertensas e intolerantes às substâncias alimentícias, além de orientações sobre o tempo de preparo e alternativas para a degustação.

O aceno a um possível epílogo para essa atividade educativa configurou-se na apresentação dos pratos típicos para os estudantes, os professores, os servidores e os técnicos dos diversos cursos e departamentos do Campus Jaru, como se pode examinar abaixo: 


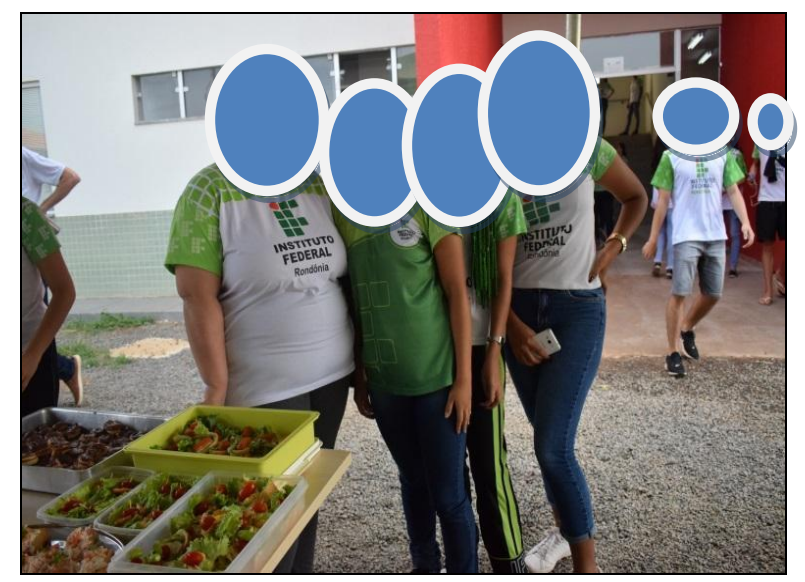

Figura 3. Apresentação dos cardápios pelos sujeitos.

Fonte: arquivo cedido aos autores pela Secretaria de Comunicação do IFRO, Campus Jaru, RO (2019).

A Figura 3, que traz discentes do segundo ano do Curso Técnico-Médio em Alimentos do IFRO, Campus Jaru, procura exibir os possíveis mergulhos nos alimentos hispano-americanos e da Região Amazônica. Durante as apresentações, os discentes se utilizaram de várias linguagens, a saber: teatro, música, coreografias, maquetes, mapas, cartazes, exposição de objetos, entre outras. As comidas, como num convite aos paladares curiosos, foram expostas em uma mesa, compondo um mosaico culinário; após as apresentações dos estudantes, a alimentação foi socializada entre discentes, docentes e visitantes.

Numa possível disposição culinária através da língua espanhola, observaram-se ações educativas que contribuíram para a emancipação dos sujeitos, num diálogo com a vida cultural, artística e social, ampliando assim os repertórios educativos com o espanhol no universo das ciências humanas do Ensino Técnico-Médio do IFRO.

\section{Que venha o próximo projeto educativo: considerações finais}

As ações educativas em espanhol se inspiraram na concepção de linguagem como elemento indissociável das práticas sociais (BAKHTIN, 2012), buscando mobilizar saberes em diálogo com a vida, numa viagem cujos pressupostos teórico-metodológicos dialogam com as orientações para 0 Ensino Médio presentes na BNCC (BRASIL, 2018a), no tocante às dimensões das ações educativas que devem articular os eixos dos conhecimentos que compõem as áreas do currículo escolar, como trabalho, ciência, tecnologia, cultura, entre outras; este assunto é o da educação.

Considerando que "Ensinar não é transferir conhecimento, mas criar possibilidades para a sua própria construção" (FREIRE, 2003, p. 47), as práticas buscaram valorizar a língua como atividade sociointerativa que se desenvolve em contextos naturais, reais e interculturais, pela qual se 
movimentam os diversos gêneros textuais discursivos (MARCUSCHI, 2006), de modo a envolver os educandos em experiências significativas e contextualizadas de aprendizagem.

A realização do Projeto consistiu de ações educativas com a língua espanhola visando à promoção de oportunidades para que os discentes pesquisassem e tivessem contato com linguagens culturais, artísticas, culinárias e linguísticas, favorecendo assim 0 interesse dos estudantes em apreender este idioma, que também é utilizado como comunicação e interação em nível mundial.

O Cardápio Educativo nos permitiu ver com outros olhos as iniciativas individuais e em coletivo, a habilidade de falar e pronunciar novos vocábulos em espanhol, as variedades alimentares dos povos hispano-americanos, inclusive os da Região Amazônica, a promoção da socialização, assim como o protagonismo dos discentes durante a atividade. No esforço de retomar a epígrafe deste estudo, na voz de Drummond (2012, p. 21), será que "as coisas findas muito mais que lindas, essas ficarão?".

Sem a pretensão de esgotar o debate sobre as práticas educativas de espanhol na escola, quem sabe, seja importante refletir que o educador pode descobrir sabores, matizes, nuances, cores e fragrâncias em companhia dos discentes; nessa acepção, talvez o ensino de língua espanhola possa ser uma poesia encontrada nas salas de aula da Educação Básica do estado de Rondônia.

\section{Referências}

ANDRADE, C. D. de. Claro enigma: Carlos Drummond de Andrade. 1 ed. São Paulo: Companhia das Letras, 2012. 144p.

ARROYO, M. Currículo: território em disputa. 5. ed. Petrópolis, RJ: Vozes, 2013. 376p.

BAKHTIN, M. Estética da criação verbal. 3. ed. Tradução: Maria Ermantina Galvão G. Pereira. São Paulo: Martins Fontes, 1999. 512p.

BAKHTIN, M. (V. Volochínov) Marxismo e Filosofia da Linguagem. 13. ed. São Paulo: Hucitec, 2012. 196p.

BRASIL. Lei $n^{0}$ 6.921, de 16 de junho de 1981. Autoriza a criação de municípios no Território Federal de Rondônia, altera a Lei $n^{0}$ 6.448, de 11 de outubro de 1977, e dá outras providências. Diário Oficial da União: Brasília, DF, Seção 1, p. 11373, 17 jun. 1981.

BRASIL. Lei $n^{0}$ 9.394, de 20 de dezembro de 1996. Estabelece as diretrizes e bases da educação nacional. Diário Oficial da União: Brasília, DF, Seção 1, p. 27833, 23 dez. 1996.

BRASIL. Decreto $n^{0} 2.208$, de 17 de abril de 1997. Regulamenta o $\S 2^{\circ}$ do art. 36 e os artigos 39 a 42 da Lei $n^{0}$ 9.394, de 20 de dezembro de 1996, que estabelece as diretrizes e bases da educação nacional. Diário Oficial da União: Brasília, DF, Seção 1, p. 7760, 18 abr. 1997. 
BRASIL. Secretaria de Educação Fundamental. Parâmetros Curriculares Nacionais: terceiro e quarto ciclos do ensino fundamental língua estrangeira. Brasília, DF: SEF, 1998.

BRASIL. Decreto $n^{0} 5.154$ de 23 de julho de 2004. Regulamenta o $\S 2^{\circ}$ do art. 36 e os arts. 39 a 41 da Lei $n^{0}$ 9.394, de 20 de dezembro de 1996, que estabelece as diretrizes e bases da educação nacional, e dá outras providências. Diário Oficial da União: Brasília, DF, Seção 1, p. 18, 26 jul. 2004.

BRASIL. Lei $n^{0} 11.161$, de 5 de agosto de 2005. Dispõe sobre o ensino da língua espanhola. Diário Oficial da União: Brasília, DF, Seção 1, p. 1, 8 ago. 2005.

BRASIL. Ministério da Educação. Secretaria de Educação Profissional e Tecnológica. Educação Profissional Técnica de Nivel Médio Integrada ao Ensino Médio. Documento-base. Brasília, DF: MEC, 2007a.

BRASIL.Decreto $n^{0}$ 6.302, de 12 dezembro de 2007.Institui o Programa Brasil Profissionalizado. Diário Oficial da União: Brasília, DF, Seção 1, p. 4, 13 dez. 2007b.

BRASIL. Lei n ${ }^{0}$ 11.892, de 29 de dezembro de 2008. Institui a Rede Federal de Educação Profissional, Científica e Tecnológica, cria os Institutos Federais de Educação, Ciência e Tecnologia, e dá outras providências. Diário Oficial da União: Brasília, DF, Seção 1, p. 1, 30 dez. 2008.

BRASIL. Programa Brasil Profissionalizado. Portal MEC, Brasília, DF, [201-?]. Disponível em: https://bit.ly/37JfxOr. Acesso em: 10 abr. 2020.

BRASIL. Lei $n^{0} 13.415$, de 16 de fevereiro de 2017. Altera as Leis $n^{\circ} 9.394$, de 20 de dezembro de 1996, que estabelece as diretrizes e bases da educação nacional, e 11.494, de 20 de junho 2007, que regulamenta o Fundo de Manutenção e Desenvolvimento da Educação Básica e de Valorização dos Profissionais da Educação, a Consolidação das Leis do Trabalho - CLT, aprovada pelo Decreto-Lei ${ }^{0}$ 5.452, de $1^{0}$ de maio de 1943, e o Decreto-Lei $n^{0} 236$, de 28 de fevereiro de 1967; revoga a Lei $n^{0}$ 11.161, de 5 de agosto de 2005; e institui a Política de Fomento à Implementação de Escolas de Ensino Médio em Tempo Integral. Diário Oficial da União: Brasília, DF, Seção 1, p. 1, 17 fev. 2017.

BRASIL. Base Nacional Comum Curricular (BNCC). Educação é a Base. Ensino Médio. Brasília, MEC, 2018a. Disponível em: https://bit.ly/3aQVDCU. Acesso em: 10 abr. 2020.

BRASIL.Ministério da Educação. Conselho Nacional de Educação. Câmara de Educação Básica. Resolução $n^{0} 3$, de 21 de novembro de 2018b. Diretrizes Curriculares Nacionais para o Ensino Médio. Diário Oficial da União: Brasília, DF, Seção 1, p. 21-24, 22 nov. 2018.

CANDAU, V. M. Diferenças culturais, interculturalidade e educação em direitos humanos. Educação \& Sociedade, Campinas, v. 33, n. 118, p. 235-250, 2012. Disponível em: https://bit.ly/3pNGwyE. Acesso em: 20 set. 2020.

CARDÁPIO Digital em Jaru, RO. OiMenu, [S. I.], [201-?]. Disponível em: https://bit.ly/3sHmDLc. Acesso em: 20 set. 2020.

CARLOU, A. Inclusão na Educação Profissional: visão dos gestores do IFRJ. 2014. Dissertação (Mestrado em Educação) - Universidade do Estado do Rio de Janeiro, Rio de Janeiro, 2014.

CELADA, M. T. Espanhol para brasileiros: uma língua singularmente estrangeira. 2002. 275 f. Tese (Doutorado em Educação) - Universidade Estadual de Campinas, Campinas, 2002. Disponível em: https://bit.ly/3qS52jh. Acesso em: 12 abr. 2020. 
CERTEAU, M. A invenção do cotidiano. 21. ed. Petrópolis, RJ: Vozes, 1994. 320 p.

CHARTIER, R. Formas e sentido. Cultura escrita: entre distinção e apropriação. 1. ed. São Paulo: Mercado de Letras, 2003. $168 \mathrm{p}$.

FIORIN, J. Elementos de análise do discurso. 1. ed. São Paulo: Contexto, 2008. 126 p.

FREIRE, P. Pedagogia da Autonomia: saberes necessários à prática educativa. São Paulo: Paz e Terra, 2003.

HALL, S. Da diáspora: identidades e mediações culturais. 2. ed. Belo Horizonte: UFMG, 2013. 480p.

INSTITUTO FEDERAL DE RONDÔNIA. Plano de Desenvolvimento Institucional 2018-2022. Porto Velho: Ifro, 2018. Disponível em: https://bit.ly/301rpH. Acesso em: 20 set. 2020.

INSTITUTO FEDERAL DE RONDÔNIA. Plano da disciplina Língua Espanhola - Campus Jaru. Jaru: Ifro, 2020. Mimeo.

LEFFA, V. J. 0 professor de línguas estrangeiras. In: LEFFA, V. J. (org.). Aspectos políticos da formação do professor de línguas estrangeiras. Pelotas: Educat, 2001. v. 1, p. 333-355.

MARCUSCHI, L. A. Gêneros textuais: configuração, dinamicidade e circulação. In: KARWOSKI, Acir Mário; GAYDECZKA, Beatriz; BRITO,KarimSiebeneicher (org.) Gêneros textuais: reflexões e ensino. 2. ed. Rio de Janeiro: Lucerna, 2006. p. 23-36.

NAGLE, J. Educação e sociedade na primeira república. 1. ed. São Paulo, SP: Pedagógica e Universitária, 1976. 344p.

OLIVEIRA, I. B; SGARB, P. (org.). Redes culturais, diversidade e Educação.In: OLIVEIRA, I. B. Aprendizagens culturais cotidianas, cidadania e educação. 1. ed. São Paulo: DP\&A, 2002. p. 37- 54.

PERRENOUND, P. Dez novas competências para ensinar. 1. ed. Porto Alegre: Artmed, 2000. 162p.

RAMOS, M. N. História e política da educação profissional. 1. ed. Curitiba: Instituto Federal do Paraná, 2014. 121p.

ROSA, G. Tutaméia. 6. ed. Rio de Janeiro: Nova Fronteira, 1985.

SANDMANN, A. J. Polissemia e Homonímia. In: NEVES, M. H. de. Descrição do Português: Revista do Curso de Pós-graduação em Linguística e Língua Portuguesa, São Paulo, Ano IV, n. 1, p. 98-127, 1990.

SAVIANI, D. História, Trabalho e Educação: Comentário Sobre as Controvérsias Internas ao Campo Marxista. Revista Germinal: Marxismo e Educação em Debate, Londrina, v. 3, n. 2, p. 4-14, dez. 2011. Disponivel em: https://bit.ly/3kHqftX. Acesso em: 10. abr. 2020.

ZEICHNER, K. A formação reflexiva de professores: ideias e práticas. 1. ed. Lisboa: Educa, 1993.

Data de submissão: 03/03/2021. Data de aprovação: 18/04/2021. 